\title{
HOW TO ENHANCE SUCCESSFUL SCIENTISTS
}

\author{
Steve Schroeder \\ Schiefelbusch Institute for Life Span Studies \\ University of Kansas
}

In my view, a worthy goal of this conference would be for our regional universities to work together and go for some big ideas. I know that the natural tendency is to think small. Big ideas tend to upset everyone. But, we have seen from Jack Burn's presentation on virtual centers at the University of Missouri how powerful big ideas can be. Such ideas must be executed with care and perspicacity because of all of the different rules and regulations of different institutions and state governments, but they are possible, and they can be potent.

\section{A Vision for the Future}

I recently read a very interesting book by E. O. Wilson, the great naturalist, while I was on vacation. It was entitled, Consilience: The Unity of Knowledge (Wilson, 1998). The concept of consilience is:

"A jumping together by linking of facts and fact-based theory across disciplines to create a common groundwork of explanation. The consilience of inductions takes place when an induction, obtained from a class of facts, coincides with an induction obtained from another different class. This consilience is the test of the truth of a theory (pp. $8 \&$ 9).

Wilson then goes on to apply his notion to the sciences, to the humanities, to the arts and to religion. His point is that we must cast a wide inter-disciplinary net if we are going to save our planet. We are not exempt from evolution. We are part of it. He then mobilizes data from world population growth rates, food production capacity, and loss of important ecosystems to illustrate how interdependent these systems are. Sustainability of life on the planet is a truly big idea in which each of us could probably find a challenging niche. Perhaps bringing this idea down to the realities of the Heartland where we cherish our quality of life and our living circumstances could be an idea that we could work on together for our region of the country.

\section{What can We do as a Regional Consortium?}

Consilient goals should be consistent with our long-term quality of life and the survival of the Heartland way of living. We should use our collective intellectual resources to set common goals that we could not accomplish alone. Such a strategy implies that sometimes we may have to sacrifice or delay some of our individual priorities to promote a common consilient goal. That, to me, is the real core of 
interdisciplinary teamwork. Sometimes individual researchers, especially successful ones, might find it difficult to do. Achieving such a consensus will challenge the ingenuity of our administrators in research and development.

\section{What can We do at our Respective Universities?}

Academic freedom at a university is a time-honored tradition which requires that individuals be encouraged to pursue their own original ideas. At the University of Kansas, I call this Kansas Individualism. Kansas has a long populist tradition that needs to be respected and celebrated. Nevertheless, consilient goals imply working to unify knowledge rather than to fragment it. Research facts and theories need to be consistent not only within but also across disciplines. This means that we will need to encourage students and faculty to train themselves across disciplines. Richard Schowen's presentation was a beautiful illustration of that, and he said it far better than I could have.

\section{How can Consilience be Achieved in our Respective Units?}

Incentive Systems. Maria Carlson's presentation was an excellent analysis of the required incentive systems, and I do not need to repeat these. I was struck by how similar they are in the humanities as well as in the natural and social sciences. That is a consilient cross-validation.

Some Basic Reality Factors. Our research and development budgets, at the University of Kansas (KU) at least, are likely to remain relatively flat in the near foreseeable future. The University of Missouri seems to be doing much better than KU or Nebraska. Perhaps we should study how you do it.

A corollary is that, if we wish to grow in research and development, we will have to do it with external funding. This will be a challenge, but a good one. The federal funding situation is the best it has ever been in my 35 years of grantsmanship, and it is likely to get better in the next few years. We will never have a better chance to mount a large regional initiative than we have right now.

A second corollary is that, even though we will grow, our growth rate must keep pace with the research mega-universities, or we will fall farther behind in the competition for the best students, the best faculty, and the best scholarly support networks for our whole university. That, in the end, could be our undoing. We have no choice but to compete.

Operations Principles. Within the Life Span Institute (LSI), we have competed very successfully over the past 40 years by developing consilient areas of excellence. Our general strategy is to cluster our 100 or so grant projects around these areas of excellence in order to compete for larger center grants and program projects that in turn support individual researchers. We have been able to do this while at the same time supporting the loner who wants to do his or her own thing. However, once an 
investigator becomes part of a larger research program and sees the intellectual as well as fiscal benefits, we do not need to do much persuading and cajoling.

Our principles of operation at LSI are based on a paper on research administration written in 1987 by my predecessor, Dick Schiefelbusch. It is still the best paper I have ever read on the topic, so I am providing it for your reading pleasure. The principles are simple in conception but difficult in implementation, mainly because of the frailty of human nature. I can readily attest to this after eight years of struggling to follow them. They are:

1) A research administrator should give the greatest effort to securing favorable outcomes for colleagues.

2) A research administrator's greatest obligations are to be informed, committed, and persistent in pursuit of consensus goals and objectives.

3) A research administrator should strive to balance the functions of change, efficiency, and good will.

I commend Dr. Schiefelbusch's paper to you to see how these principles are implemented. It follows here in its entirety. 